\title{
Cushing's disease presenting with gastrointestinal perforation: a case report
}

\author{
Takuma Hara, Hiroyoshi Akutsu, Tetsuya Yamamoto, Eiichi Ishikawa, \\ Masahide Matsuda and Akira Matsumura
}

Department of Neurosurgery, Faculty of Medicine, University of Tsukuba, 1-1-1 Tennodai, Tsukuba, Ibaraki 305-0006, Japan

\author{
Correspondence \\ should be addressed \\ to H Akutsu \\ Email \\ akutsuh@md.tsukuba.ac.jp
}

\begin{abstract}
Gastrointestinal perforation is a complication associated with steroid therapy or hypercortisolism, but it is rarely observed in patients with Cushing's disease in clinical practice, and only one case has been reported as a presenting symptom. Herein, we report a rare case of Cushing's disease in which a patient presented with gastrointestinal perforation as a symptom. A 79-year-old man complained of discomfort in the lower abdomen for 6 months. Based on the endocrinological and gastroenterological examinations, he was diagnosed with Cushing's disease with a perforation of the descending colon. After consultation with a gastroenterological surgeon, it was decided that colonic perforation could be conservatively observed without any oral intake and treated with parenteral administration of antibiotics because of the mild systemic inflammation and lack of abdominal guarding. Despite the marked elevated levels of serum cortisol, oral medication was not an option because of colonic perforation. Therefore, the patient was submitted to endonasal adenomectomy to normalize the levels of serum cortisol. Subsequently, a colostomy was successfully performed. Despite its rarity, physicians should be aware that gastrointestinal perforation may be associated with hypercortisolism, especially in elderly patients, and immediate diagnosis and treatment of this life-threatening condition are essential. If a perforation can be conservatively observed, endonasal adenomectomy prior to laparotomy is an alternative treatment option for hypercortisolism.
\end{abstract}

\section{Learning points:}

- Thus far, only one case of gastrointestinal perforation as a presenting clinical symptom of Cushing's disease has been reported.

- Physicians should be aware that gastrointestinal perforation might be associated with hypercortisolism in elderly patients because elevated levels of serum cortisol may mask the clinical signs of perforation. Because of this masking effect, the diagnosis of the perforation also tends to be delayed.

- Although parenteral administration of etomidate is a standard treatment option for decreasing the elevated levels of serum cortisol, endonasal adenomectomy prior to laparotomy is an alternative treatment option if etomidate therapy is unavailable.

\section{Background}

Cushing's disease accounts for $4.7 \%$ of pituitary adenomas (1), and typically patients show clinical symptoms of impaired glucose tolerance, hypertension, central obesity, moon face, osteoporosis, and psychosis (2) (3).
Gastric/duodenal ulcers may also present as clinical symptoms in hypercortisolism patients undergoing steroid therapy (4) (5) (6) (7) (8) (9), but are rarely observed in clinical practice; thus far, only one case of a patient with Cushing's disease presenting with gastrointestinal 
perforation has been reported (10). Herein, we report a rare case of Cushing's disease in which colonic perforation was a presenting symptom.

\section{Case presentation}

A 79-year-old man with angina pectoris, hypertension, giant-cell tumor of the tendon sheath, and cataracts was admitted to our hospital in late 2008. He had also undergone surgery for prostate and gallbladder cancers, which were cured. He had smoked approximately ten cigarettes per day during his twenties. From 2005 onwards, he occasionally felt tension in his lower abdomen. Upper and lower gastrointestinal endoscopy showed only multiple colonic diverticula. Due to worsening of his lower abdominal pain, he was treated with nonsteroidal anti-inflammatory drugs (NSAIDs) since the beginning of 2008. In October 2008, he was diagnosed with diabetes mellitus, and medication therapy was started. In December 2008, he had an unsteady gait and general fatigue and his lower abdominal pain worsened. Therefore, he was admitted to our hospital.

Upon admission, the patient was $160 \mathrm{~cm}$ tall and weighed $62.7 \mathrm{~kg}$. He had a body temperature of $37.1^{\circ} \mathrm{C}$, a pulse rate of $64 \mathrm{bpm}$, and a blood pressure of $140 / 68 \mathrm{mmHg}$. He had a white tongue, moon face, mildly thinning skin, pitting edema in the extremities, extravasated blood spots on the dorsal surface of his hands, central obesity, and crural and gluteal muscle atrophy. His abdomen was flat and soft, and there were no signs of guarding or peritonitis. He had been taking aspirin, amlodipine besylate, rosuvastatin calcium, famotidine, teprenone, mosapride citrate hydrate, and glimepiride.

\section{Investigation}

Initial laboratory examination indicated hypokalemia, diabetes mellitus, and metabolic alkalosis (Table 1). There was diurnal variation in the levels of adrenocorticotropic hormone (ACTH) and cortisol, but excessive nocturnal secretion of cortisol. A corticotropin-releasing hormone (CRH) test indicated hypersecretion of ACTH, and Cushing's disease was suspected. However, an $8 \mathrm{mg}$ dexamethasone suppression test indicated that the levels of serum cortisol were not suppressed (Tables 2 and 3).

A computed tomography (CT) scan showed retroperitoneal emphysema and multiple colonic diverticula in the colon, suggesting a perforation of the descending colonic diverticula (Fig. 1). An enhanced thoracicabdominal CT scan showed bilateral adrenal hyperplasia
Table 1 Initial biochemical workup.

\begin{tabular}{ll}
\hline $\mathrm{Na}$ & $146 \mathrm{mmol} / \mathrm{l}$ \\
$\mathrm{Cl}$ & $91 \mathrm{mmol} / \mathrm{l}$ \\
$\mathrm{K}$ & $1.9 \mathrm{mmol} / \mathrm{l}$ \\
Fasting blood sugar (FBS) & $257 \mathrm{mg} / \mathrm{ml}$ \\
$\mathrm{HbA} 1 \mathrm{c}$ & $7.70 \%$ \\
Leukocyte & $9600 / \mu \mathrm{l}$ \\
Segment & $82 \%$ \\
Eosinophil & $0 \%$ \\
$\mathrm{Hb}$ & $15.5 \mathrm{~g} / \mathrm{dl}$ \\
$\mathrm{ACTH}$ & $202.8 \mathrm{pg}$ \\
$\mathrm{Cortisol}$ & $44.6 \mu \mathrm{g} / \mathrm{ml}$ \\
$\mathrm{pH}$ & 7.604 \\
$\mathrm{PCO}_{2}$ & $48.7 \mathrm{mmHg}$ \\
$\mathrm{PO}_{2}$ & $53.2 \mathrm{mmHg}$ \\
$\mathrm{HCO}$ & - \\
$\mathrm{Base}^{-}$excess (BE) & $48.7 \mathrm{mmol} / \mathrm{l}$ \\
$\mathrm{C}^{-r e a c t i v e ~ p r o t e i n ~(C R P) ~}$ & $23.7 \mathrm{mmol} / \mathrm{l}$ \\
lgG & $1.14 \mathrm{mg} / \mathrm{dl}$ \\
\hline
\end{tabular}

but no ectopic ACTH-producing tumors. Magnetic resonance imaging (MRI) of the brain showed intrasellar mass lesion with mild suprasellar extension, which suggested pituitary macroadenoma (Fig. 2). Despite the unsuppressed levels of cortisol, after the $8 \mathrm{mg}$ dexamethasone suppression test, the patient was diagnosed with Cushing's disease based on the results of the CRH test as well as the CT and MRI scans.

\section{Treatment}

Although no bacteria were detected in the blood, treatment with cefmetazole sodium ( $2 \mathrm{~g} /$ day) was started. After consultation with a gastroenterological surgeon, conservative treatment was opted for, based on the mild systemic inflammation and lack of abdominal guarding. In a patient with marked hypercortisolism, laparotomy would probably lead to perioperative complications. After restricting oral intake and initiating total parenteral nutrition transfusion treatment, the symptoms improved and the inflammation subsided. Therefore, we decided to remove the ACTH-secreting pituitary adenoma

Table 2 Serum ACTH and cortisol levels of the patient in the $\mathrm{CRH}$ test.

\begin{tabular}{|c|c|c|}
\hline & ACTH (pg/dl) & Cortisol $(\mu \mathrm{g} / \mathrm{dl})$ \\
\hline $0 \mathrm{~min}$ & 155.8 & 47.8 \\
\hline $30 \mathrm{~min}$ & 253.4 & 59.7 \\
\hline $60 \mathrm{~min}$ & 198.2 & 54.1 \\
\hline $90 \mathrm{~min}$ & 150.2 & 55.8 \\
\hline $120 \mathrm{~min}$ & 147.7 & 57.4 \\
\hline
\end{tabular}

$\mathrm{ACTH}$, adrenocorticotropic hormone; $\mathrm{CRH}$, corticotropin-releasing hormone. 
Table 3 Serum ACTH and cortisol levels in the dexamethasone suppression test and daily variations in the levels.

\begin{tabular}{|c|c|c|}
\hline & ACTH $(p g / d l)$ & Cortisol $(\mu \mathrm{g} / \mathrm{dl})$ \\
\hline 8 o'clock & $\begin{array}{l}239.8 \\
1241\end{array}$ & $\begin{array}{l}45.9 \\
34\end{array}$ \\
\hline 20 o'clock & 124.1 & 34 \\
\hline $\begin{array}{l}8 \text { mg dexametha- } \\
\text { sone test }\end{array}$ & 109.5 & 35.3 \\
\hline
\end{tabular}

endonasally to decrease the levels of serum cortisol before performing abdominal surgery. The levels of serum cortisol could not be suppressed by oral medication because of perforations in the digestive tract. Furthermore, no parenteral medication for suppressing the levels of serum cortisol, such as etomidate, is available in Japan. On day 15 , the tumor was totally resected endonasally, and it showed typical signs of pituitary adenoma. It was whitish, soft, fragile, and well demarcated. An ACTH-secreting pituitary adenoma was histologically diagnosed.

\section{Outcome and follow-up}

There was a dramatic postoperative improvement in hypokalemia and hypercortisolism. Because the levels of serum cortisol decreased below the normal limit, replacement therapy with hydrocortisone was started after endonasal adenomectomy. After the levels of serum cortisol were normalized, a colostomy for diverticular perforation was performed by a gastroenterological surgeon on day 42 . Abscess and minor perforation of multiple colonic diverticula were observed. The patient was discharged without any postoperative complications and was started on prednisolone replacement therapy ( $4 \mathrm{mg} / \mathrm{day})$.

\section{Discussion}

\section{Hypercortisolism and gastrointestinal perforation}

Cushing's disease presents with various clinical symptoms because of the excessive production of ACTH (2) (3) (11) (12). Lower gastrointestinal perforation has been reported only once as a clinical symptom of Cushing's disease (10). Gastrointestinal perforations are mainly caused by stress, excessive secretion of digestive fluid, or gastrointestinal tumors (6) (13) (14) (15). The association between diverticular perforation and hypercortisolism is still controversial. However, there are several reports of oral steroid therapy leading to gastrointestinal perforation (4) (15) (16) (17) (18) (19) (20) (21) (22) (23) (24). Excessive levels of steroids may cause gastrointestinal perforation by thinning the bowel lymphoid tissue, thereby diminishing resistance to bacterial invasion, slowing down the turnover of intestinal mucosal cells, and decreasing fibroblastic reparative activity (25). Similar mechanisms may have occurred in our patient.

Gastrointestinal perforation may also result from an increased vulnerability of the tissue, which in turn results from the increased secretion of glucocorticoids, a symptom of Cushing's disease (4) (8) (9). Elderly patients generally tend to experience increased tissue vulnerability. Therefore, elderly Cushing's patients are at a greater risk of tissue vulnerability in addition to long-standing hypercortisolism. Cushing's disease generally occurs in individuals between the ages of 30 and 50 years (2). As our patient was aged above this range, he might have been at a higher risk of gastrointestinal perforation.

Direct associations between hypercortisolism and diverticular perforation are extremely rare, but an indirect association (i.e. masking effect of hypercortisolism) has been suggested (4) (26). In the case reported herein, the diagnosis of gastrointestinal perforation was complicated because of the masking of the inflammatory response by an elevated level of cortisol. Therefore, the clinical situation could have been worse than it appeared in our patient. The elevated neutrophil count may have been due to elevated serum cortisol levels and/or sepsis. When treating patients with hypercortisolism, physicians should be aware that an elevated level of cortisol could mask serious conditions such as sepsis and peritonitis.

The perforation of colonic diverticula is a well-known life-threatening side effect of steroid therapy and has been reported in $\sim 2.7 \%$ of patients undergoing steroid treatment for colonic diverticula (8). The risk of perforation increases in the elderly and oral steroid users. Colonic diverticula and long-term hypercortisolism resulting from oral steroid
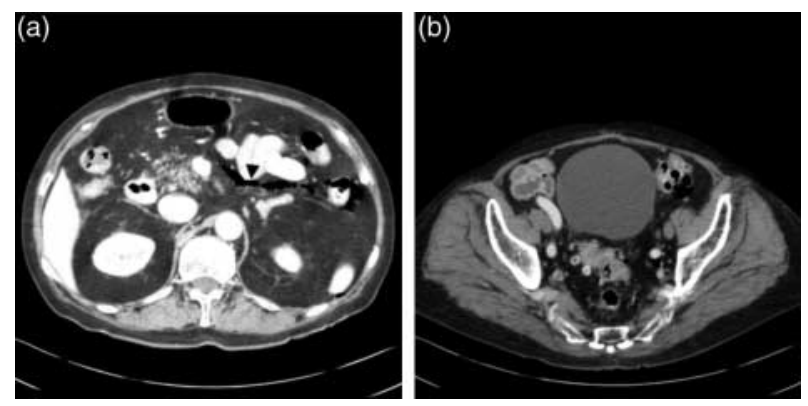

Figure 1

(a) Enhanced CT image of the patient's abdomen showing free air around the sigmoid colon, transverse colon, and descending colon (arrowhead). (b) Enhanced CT image of the patient's abdomen showing numerous sigmoid colon diverticula with stercoroma in the diverticulum. 

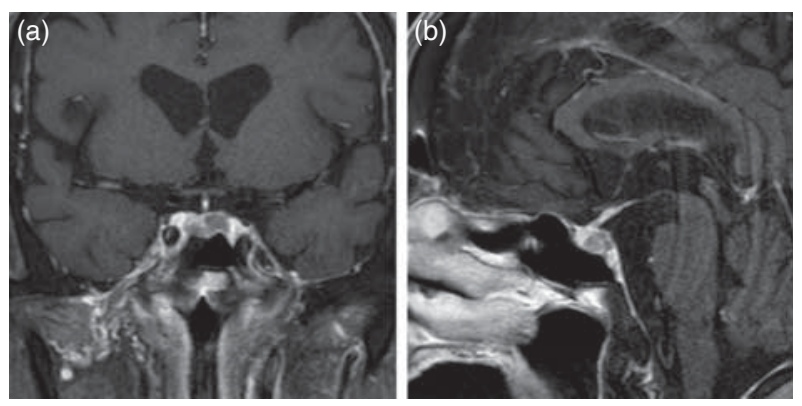

Figure 2

Coronal (a) and sagittal (b) T1-weighted MR images with gadolinium showing an intrasellar mass lesion with slight suprasellar extension.

therapy affect the development of gastrointestinal perforation (4) (5) (6) (7) (8) (9). The prevalence of colonic diverticula increases with age. While $16-22 \%$ of individuals aged below 40 years have colonic diverticula, 42-60\% of individuals aged above 80 years are expected to have this condition (27) (28). However, $80-85 \%$ of patients with diverticula experience no symptoms over a lifetime (29).

The pathological features of duodenal diverticular perforation combined with steroid and NSAID use have been reported (8). Histopathological examination of the diverticula showed invagination of the mucosa through the submucosa and muscularis propria. The muscle layer including the diverticula was thinned, and there was little or no inflammation. The absence of increased inflammation and distortion of the mucosal crypt vessel architecture rules out chronic inflammatory conditions and favors our theory that these perforations were drug induced. The infiltration of neutrophils signifies the presence of infection, which may be secondary to the drugs (8). In the case reported herein, because the site of perforation was not resected, the pathological findings are unknown.

\section{Endocrinological findings}

Regarding the cause of the false negative suppression of cortisol in the $8 \mathrm{mg}$ dexamethasone suppression test, we believe that oral absorption was diminished because of the gastrointestinal perforation. In addition, the $\mathrm{CRH}$ test indicated a discrepancy between the ACTH and cortisol responses: a compatible response of ACTH and an insufficient response of cortisol. This is most likely because the adrenal cortex had been secreting the maximal level of cortisol and could no longer respond. Endocrinological findings should be carefully evaluated in a patient with gastrointestinal perforation or marked elevated levels of cortisol.

\section{Treatment strategy}

Perioperative mortality is a well-known risk factor in patients with marked hypercortisolemia. Therefore, attempts should be made to decrease the levels of serum cortisol with medication such as metyrapone or ketoconazole prior to surgery (30). However, in cases of gastrointestinal perforation such as the one reported here, oral medication therapy is not possible. Parenteral administration of etomidate is an alternative option to decrease the levels of serum cortisol (30) (31). Unfortunately, etomidate is not available in Japan. In the case reported here, endonasal adenomectomy successfully resulted in a decrease in the levels of serum cortisol without any perioperative complication. If available, parenteral etomidate therapy prior to endonasal adenomectomy would be a safer treatment option. In general, gastrointestinal tract perforation should be treated immediately regardless of any other complications, because it is a fatal condition. Gastroenterological surgery under marked hypercortisolemia is also associated with a high mortality rate. Therefore, if gastrointestinal perforation can be treated with conservative therapy, attempts should be made to decrease the levels of cortisol prior to laparotomy. We performed an endonasal adenomectomy to decrease the levels of serum cortisol prior to laparotomy. A colostomy was safely performed in our patient without perioperative complications after the levels of serum cortisol were normalized.

Declaration of interest

The authors declare that there is no conflict of interest that could be perceived as prejudicing the impartiality of the research reported.

\section{Funding}

This research did not receive any specific grant from any funding agency in the public, commercial or not-for-profit sector.

\section{Patient consent}

Written informed consent has been obtained from the patient's daughter for publication of the case report.

\section{Author contribution statement}

$\mathrm{H}$ Akutsu was the physician responsible for the patient and he reviewed and edited the manuscript. T Yamamoto, E Ishikawa, M Matsuda, and A Matsumura were the patient's physicians. 


\section{References}

1 Ambrosi B \& Faglia G 1991 Epidemiology of pituitary tumors. Excerpta Medica International Congress Series 961 159-168.

2 Etxabe J \& Vasquez JA 1994 Morbidity and mortality in Cushing's disease: an epidemiological approach. Clinical Endocrinology 40 479-484. (doi:10.1111/j.1365-2265.1994.tb02486.x)

3 Nieman LK, Biller BM, FindlingJW, Newell-Price J, Savage MO, Stewart PM \& Montori VM 2008 The diagnosis of Cushing's syndrome: an Endocrine Society Clinical Practice Guideline. Journal of Clinical Endocrinology and Metabolism 93 1526-1540. (doi:10.1210/jc.2008-0125)

4 Goethals L, Nieboer K, De Smet K, De Geeter E, Tabrizi NH, Van Eetvelde E \& de May J 2011 Cortisone associated diverticular perforation. Journal Belge de Radiologie - Belgisch Tijdschrift voor Radiologie 94 348-349.

5 Kouyialis A, Boviatsis E \& Sakas D 2006 Oral steroids as a cause of diverticulum perforation. Lancet 367 83. (doi:10.1016/S01406736(06)67929-4)

6 Mpofu S, Mpofu CM, Hutchinson D, Maier AE, Dodd SR \& Moots RJ 2004 Steroids, non-steroidal anti-inflammatory drugs, and sigmoid diverticular abscess perforation in rheumatic conditions. Annals of Rheumatic Disease 63 588-590. (doi:10.1136/ard.2003.010355)

7 Munsch B, Chauffert B, Cuny C, Lorcerie B \& Martin F 1995 Perforation of colonic diverticulum under corticoids: a complication to be known and recognized (in French). La Revue de Médecine Interne 16 137-140. (doi:10.1016/0248-8663(96)80678-3)

8 Palanivelu C, Rangarajan M, Rajapandian S, Maheshkumaar GS \& Madankumar MV 2008 Perforation of jejunal diverticula in steroids and nonsteroidal anti-inflammatory drug abusers: a case series. World Journal of Surgery 32 1420-1425. (doi:10.1007/s00268-008-9469-0)

9 Sharma R, Gupta KL, Ammon RH \& Gambert SR 1997 Atypical presentation of colon perforation related to corticosteroid use. Geriatrics 52 88-90.

10 de Havenon A \& Ehrenkranz J 2011 A perforated diverticulum in Cushing's disease. International Journal of Surgery Case Reports 2 215-217. (doi:10.1016/j.ijscr.2011.06.009)

11 Oki Y, Hashimoto K, Hirata Y, Iwasaki Y, Nigawara T, Doi M, Sakihara S, Kageyama K \& Suda T 2009 Development and validation of a $0.5 \mathrm{mg}$ dexamethasone suppression test as an initial screening test for the diagnosis of ACTH-dependent Cushing's syndrome. Endocrine Journal 56 897-904. (doi:10.1507/endocrj.K09E-194)

12 Suda T, Kageyama K, Nigawara T \& Sakihara S 2009 Evaluation of diagnostic tests for ACTH-dependent Cushing's syndrome. Endocrine Journal 56 469-476. (doi:10.1507/endocrj.K08E-353)

13 Ellershaw JE \& Kelly MJ 1994 Corticosteroids and peptic ulceration. Palliative Medicine 8 313-319. (doi:10.1177/026921639400800407)

14 Markowits AM 1960 The less common perforations of the small bowel. Annals of Surgery 152 240-257. (doi:10.1097/00000658-19600800000006)

15 Piekarek K \& Israelsson LA 2008 Perforated colonic diverticular disease: the importance of NSAIDs, opioids, corticosteroids, and calcium channel blockers. International Journal of Colorectal Disease $\mathbf{2 3}$ 1193-1197. (doi:10.1007/s00384-008-0555-4)
16 Fadul CE, Lemann W, Thaler HT \& Posner JB 1988 Perforation of the gastrointestinal tract in patients receiving steroids for neurologic disease. Neurology 38 348-352. (doi:10.1212/WNL.38.3.348)

17 Glenn F \& Grafe WR, Jr 1967 Surgical complications of adrenal steroid therapy. Annals of Surgery 165 1023-1034. (doi:10.1097/00000658196706000-00017)

18 Kim SH, Shin SS, Jeong YY, Heo SH, Kim JW \& Kang HK 2009 Gastrointestinal tract perforation: MDCT findings according to the perforation sites. Korean Journal of Radiology 10 63-70. (doi:10.3348/kjr. 2009.10.1.63)

19 Morris CR, Harvey IM, Stebbings WS, Speakman CT, Kennedy HJ \& Hart AR 2003 Anti-inflammatory drugs, analgesics and the risk of perforated colonic diverticular disease. British Journal of Surgery 90 1267-1272. (doi:10.1002/bjs.4221)

20 ReMine SG \& McIlrath DC 1980 Bowel perforation in steroid-treated patients. Annals of Surgery 192 581-586. (doi:10.1097/00000658198010000-00016)

21 Sterioff S, Orringer MB \& Cameron JL 1974 Colon perforations associated with steroid therapy. Surgery 75 56-58.

22 Venditti D, Valerio B, Ielpo B, Buonomo O \& Petrella G 2011 Bowel perforations in a patient affected by Churg-Strauss syndrome under high-dose steroid treatment: will alternative drugs reduce risk of surgery? Rheumatology International 31 1239-1241. (doi:10.1007/ s00296-009-1289-5)

23 Warshaw AL, Welch JP \& Ottinger LW 1976 Acute perforation of the colon associated with chronic corticosteroid therapy. American Journal of Surgery 131 442-446. (doi:10.1016/0002-9610(76)90154-9)

24 Weiner HL, Rezai AR \& Cooper PR 1993 Sigmoid diverticular perforation in neurosurgical patients receiving high-dose corticosteroids. Neurosurgery 33 40-43. (doi:10.1227/00006123-19930700000006)

25 Rigotti P, Van Buren CT, Payne WD, Peters C \& Kahan BD 1986 Gastrointestinal perforations in renal transplant recipients immunosuppressed with cyclosporin. World Journal of Surgery 10 137-141. (doi:10.1007/BF01656107)

26 Kouyialis A, Sakas D, Boviatsis E, Maratheftis N \& Korfias S 2003 Delayed diagnosis of steroid-induced colon diverticulum perforation. New Zealand Medical Journal 1161183.

27 Painter NS \& Burkitt DP 1971 Diverticular disease of the colon: a deficiency disease of western civilization. BMJ 2 450-454. (doi:10.1136/bmj.2.5759.450)

28 Painter NS \& Burkitt DP 1975 Diverticular disease of the colon, a 20th century problem. Clinics in Gastroenterology 4 3-21.

29 Stollman N \& Raskin JB 2004 Diverticular disease of the colon. Lancet 363 631-639. (doi:10.1016/S0140-6736(04)15597-9)

30 Drake WM, Perry LA, Hinds CJ, Lowe DG, Reznek RH \& Besser GM 1998 Emergency and prolonged use of intravenous etomidate to control hypercortisolemia in a patient with Cushing's syndrome and peritonitis. Journal of Clinical Endocrinology and Metabolism 83 3542-3544. (doi:10.1210/jc.83.10.3542)

31 Heyn J, Geiger C, Hinske CL, Briegel J \& Weis F 2012 Medical suppression of hypercortisolemia in Cushing's syndrome with particular consideration of etomidate. Pituitary 15 117-125. (doi:10.1007/s11102-011-0314-3)

Received in final form 7 October 2013

Accepted 30 October 2013 